ARTICLE

\title{
High crystallinity design of Ir-based catalysts drives catalytic reversibility for water electrolysis and fuel cells
}

\author{
Woong Hee Lee ${ }^{1}$, Young-Jin Ko${ }^{2}$, Jung Hwan Kim ${ }^{3}$, Chang Hyuck Choi (i) ${ }^{4}$, Keun Hwa Chae (i) ${ }^{5}$, \\ Hansung Kim (1) ${ }^{3}$, Yun Jeong Hwang (10) ${ }^{6,7}$, Byoung Koun Min (1) ${ }^{1,8}$, Peter Strasser (D) ${ }^{9 凶} \&$ \\ Hyung-Suk Oh (1) 1,10,11凶
}

The voltage reversal of water electrolyzers and fuel cells induces a large positive potential on the hydrogen electrodes, followed by severe system degradation. Applying a reversible multifunctional electrocatalyst to the hydrogen electrode is a practical solution. Ir exhibits excellent catalytic activity for hydrogen evolution reactions (HER), and hydrogen oxidation reactions (HOR), yet irreversibly converts to amorphous $\mathrm{IrO}_{\mathrm{x}}$ at potentials $>0.8 \mathrm{~V} / \mathrm{RHE}$, which is an excellent catalyst for oxygen evolution reactions (OER), yet a poor HER and HOR catalyst. Harnessing the multifunctional catalytic characteristics of Ir, here we design a unique Ir-based electrocatalyst with high crystallinity for OER, HER, and HOR. Under OER operation, the crystalline nanoparticle generates an atomically-thin $\mathrm{IrO}_{x}$ layer, which reversibly transforms into a metallic Ir at more cathodic potentials, restoring high activity for HER and HOR. Our analysis reveals that a metallic Ir subsurface under thin $\operatorname{IrO}_{x}$ layer can act as a catalytic substrate for the reduction of Ir ions, creating reversibility. Our work not only uncovers fundamental, uniquely reversible catalytic properties of nanoparticle catalysts, but also offers insights into nanocatalyst design.

\footnotetext{
${ }^{1}$ Clean Energy Research Center, Korea Institute of Science and Technology (KIST), Seoul, Republic of Korea. ${ }^{2}$ Center for Electronic Materials, Korea Institute of Science and Technology (KIST), Seoul, Republic of Korea. ${ }^{3}$ Department of Chemical and Biomolecular Engineering, Yonsei University, Seoul, Republic of Korea. ${ }^{4}$ School of Materials Science and Engineering, Gwangju Institute of Science and Technology, Gwangju, Republic of Korea. ${ }^{5}$ Advanced Analysis Center, Korea Institute of Science and Technology (KIST), Seoul, Republic of Korea. ${ }^{6}$ Department of Chemistry, Seoul National University, Seoul, South Korea.

${ }^{7}$ Center for Nanoparticle Research, Institute for Basic Science (IBS), Seoul, South Korea. ${ }^{8}$ Graduate School of Energy and Environment (KU-KIST Green School), Korea University, Seoul, Republic of Korea. ${ }^{9}$ The Electrochemical Energy, Catalysis, and Materials Science Laboratory, Department of Chemistry, Chemical Engineering Division, Technical University Berlin, Berlin, Germany. ${ }^{10}$ Division of Energy and Environmental Technology, KIST School, Korea University of Science and Technology, Seoul, Republic of Korea. ${ }^{11} \mathrm{KHU}-\mathrm{KIST}$ Department of Conversing Science and Technology, Kyung Hee University, Seoul, Republic of Korea. ${ }^{凶}$ email: pstrasser@tu-berlin.de; hyung-suk.oh@kist.re.kr
} 
$\mathrm{n}$ view of a clean and renewable society, there has been great interest in water electrolysis and fuel cells for producing and using hydrogen, which is considered a promising energy carrier $^{1,2}$. Water electrolysis consists of a two-electrode reaction: a hydrogen evolution reaction (HERs) and an oxygen evolution reaction $(\mathrm{OERs})^{3,4}$. Fuel cells produce electricity through twoelectrode reactions: hydrogen oxidation (HOR) and oxygen reduction $(\mathrm{ORR})^{5}$. Recent studies have reported that unexpected operating conditions, such as a sudden shut-down and fuel starvation, induce voltage reversal to corrode hydrogen electrodes, degrading the durability of the systems. When shut-down occurs in water electrolysis, the potential of the hydrogen electrode is increased, leading to degradation at the hydrogen electrode ${ }^{6,7}$. In polymer electrolyte membrane (PEM) fuel cell operation, fuel starvation occurring at the anode side leads to a voltage reversal phenomenon, causing corrosion of carbon components like catalyst support, gas diffusion layer (GDL) and flow field plate on the anode ${ }^{8,9}$. A recent study proposed reducing the damage to the electrode by selectively promoting HOR catalysts by suppressing the $\mathrm{ORR}^{10}$ and introducing a water oxidation catalyst to the anode of the PEM fuel cell to induce an OER, as it is a reaction that competes with the carbon corrosion reaction ${ }^{9}$. In this regard, multifunctional catalysts can be a promising strategy in environments where the electrochemical reaction changes rapidly, such as the voltage reversal of water electrolysis and PEM fuel cell systems.

Among the various catalysts, Ir-based materials are excellent candidates to fit this strategy owing to their remarkable OER activity as well as good HER and HOR catalytic activity ${ }^{11-14}$. In particular, an amorphous $\mathrm{IrO}_{\mathrm{x}}$ surface is considered the best active site for OER ${ }^{15,16}$. Based on the X-ray photoemission spectroscopy (XPS) and X-ray absorption spectroscopy (XAS), amorphous $\mathrm{IrO}_{\mathrm{x}}\left(\mathrm{Ir}^{\mathrm{III}}\right)$ exhibits a higher oxidation state than rutile $\mathrm{IrO}_{2}\left(\mathrm{Ir}^{\mathrm{IV}}\right)$ due to abundant electrophilic oxygen species $\left(\mathrm{O}^{\mathrm{I}}\right)$ which cause nucleophilic attack of water, leading to enhanced OER catalytic activity ${ }^{17-19}$. For HER and HOR, it has been reported that metallic-Ir surfaces such as $\operatorname{Ir}$ (111) show significant catalytic activities ${ }^{20,21}$. Thus, Ir-based materials possess good OER, HER and HOR catalytic activity and can be used as anodes and cathodes of water electrolyzers and as anodes of PEM fuel cells. However, despite the multifunctionality of Irbased catalysts, the inconsistent active sites and irreversibility of Ir for HER, HOR, and OER have limitations in their application to real device systems with varying operating conditions. The Strasser group reported that Ir nanoparticles irreversibly changed to oxide formation under potential cycling over $1.0 \mathrm{~V}_{\mathrm{RHE}}{ }^{14}$. Fuel starvation in PEM fuel cells or voltage reversal in water electrolysis occurs, and irreversible oxidation of Ir-based catalyst would happen at the anode in the fuel cell and at the cathode in water electrolyzers, resulting in the loss of multifunctional catalytic properties. Therefore, securing the reversible properties of Ir nanoparticles can be a viable alternative that can improve the durability of fuel cells and water electrolysis systems while maintaining multifunctional catalytic properties.

Herein, we introduce a crystalline Ir-based alloy catalyst as a strategy to maintain the electrochemical reversibility of Ir. Alloying Ir with a transition metal is an efficient method to improve the kinetics of the OER, HER and $\mathrm{HOR}^{22,23}$. We synthesize carbon-supported IrNi alloy nanoparticles with high crystallinity ( $\mathrm{IrNi} / \mathrm{C}-\mathrm{HT})$ and with low crystallinity ( $\mathrm{IrNi} / \mathrm{C}-\mathrm{LT})$, both of which exhibited excellent OER/HER/HOR catalytic activity. Based on the results of in situ/operando X-ray absorption near edge structure (XANES) and depth-resolved XPS, HER and HOR performance of IrNi/C-LT sharply decreased after the OER measurement, due to conversion of the irreversible amorphous $\mathrm{IrNiO}_{\mathrm{x}}$ surface. However, IrNi/C-HT possesses a very thin $\mathrm{IrNiO}_{\mathrm{x}}$ layer under the OER condition and this $\mathrm{IrNiO}_{\mathrm{x}}$ layer is reversibly converted to a metallic surface under the HER condition, exhibiting high HER performance. We explored the mechanism of the reversible $\mathrm{IrNiO}_{\mathrm{x}}$ layer of $\mathrm{IrNi} / \mathrm{C}$-HT using electrochemical flowcell coupling operando inductively coupled plasma-mass spectrometry (ICP-MS). In addition, the prepared catalysts were applied to the fuel starvation of the PEM fuel cell and the reverse voltage of the water electrolyzer to confirm their viability in a real environment.

\section{Results}

IrNi/C morphology and crystallinity: synthesis temperature. IrNi nanoparticles supported on carbon $(\mathrm{IrNi} / \mathrm{C})$ were synthesized using a modified impregnation method that instantly changed to reductive gas conditions at target heat-treatment temperatures, to control the crystallinity while maintaining a small particle size. Carbon was used as the model support for observing nanocatalyst properties. Synthesized $\mathrm{IrNi} / \mathrm{C}$ materials treated at $400^{\circ} \mathrm{C}$ and $1000^{\circ} \mathrm{C}$ were denoted as $\mathrm{IrNi} / \mathrm{C}-\mathrm{LT}$ and $\mathrm{IrNi} / \mathrm{C}-\mathrm{HT}$, respectively. For comparison, Ir/C-LT and $\mathrm{Ir} / \mathrm{C}-\mathrm{HT}$ were prepared by the same method without the nickel precursor. The high-resolution transmission electron microscopy (HRTEM) images of IrNi/C-LT and -HT (Fig. 1a, d) show a similar particle size $(1-1.5 \mathrm{~nm})$ and distribution. Energy-dispersive $\mathrm{X}$ ray (EDX) mapping images of the $\mathrm{IrNi} / \mathrm{C}$ catalysts (Supplementary Figs. 1-3) reveal that Ir and Ni elements are moderately distributed on the carbon support, suggesting the presence of an Ir and Ni alloy. Based on the TEM EDX images (Supplementary Fig. 4), the atomic ratios of Ir:Ni were 78:21 and 66:34 for $\mathrm{IrNi} /$ $\mathrm{C}-\mathrm{LT}$ and $\mathrm{IrNi} / \mathrm{C}-\mathrm{HT}$, respectively. However, as shown in the high-angle annular dark field (HADDF) image (Fig. 1b, c, e, f), IrNi/C-LT showed a polycrystalline and amorphous structure with low crystallinity, whereas IrNi/C-HT displayed an almost single crystal character with high crystallinity. The IrNi/C-HT nanoparticles exhibited (111) and (200) facets, suggesting [011] FCC single-crystal structure. The above crystallinity differences were confirmed by X-ray diffraction (XRD) (Supplementary Fig. 5). The (111) reflection of $\mathrm{IrNi} / \mathrm{C}-\mathrm{HT}$ was located at $41.1^{\circ}$, upshifted relative to that of metallic Ir at $40.6^{\circ}$ (see JCPDS no. 87-0715), suggesting a disordered Ir-Ni alloy. In contrast, an Ir alloy peak was not observed for $\mathrm{IrNi} / \mathrm{C}-\mathrm{LT}$ due to its small particle size and low crystallinity. Sharp XRD reflections as well as HR-TEM images confirmed the presence of few large $\mathrm{Ni}$ particles (Supplementary Fig. 6). A similar relation between temperature and crystallinity at comparable particle size was observed for the pure Ir/C catalysts (Supplementary Figs. 7 and 8). Based on these results, we concluded that controlling the crystallinity of $\mathrm{IrNi} / \mathrm{C}$ catalysts by the annealing temperature at comparable $1 \sim 2 \mathrm{~nm}$ particle size and alloy atomic ratios was achieved. The rational reason for the small particle sizes with high crystallinity as described above is as follows. First, the dry product of carbon support with $\mathrm{Ir}$ and $\mathrm{Ni}$ precursor containing solution leads to $\mathrm{Ir}$ and $\mathrm{Ni}$ ions attaching to the carbon support in atomic-scale fine dispersion. These are hardly reduced in $\mathrm{N}_{2}$ without $\mathrm{H}_{2}$ gas even at high temperatures. This prevents Ostwald ripening/agglomeration during thermal treatments of up to $1000^{\circ} \mathrm{C}$. Second, when the $\mathrm{N}_{2}$ gas was immediately changed to $10 \% \mathrm{H}_{2}(99.999 \%)$ and $90 \% \mathrm{~N}_{2}$ at $1000{ }^{\circ} \mathrm{C}$, reduction occurred quickly, leading to a higher nucleation density and a finer nuclei size. This effect can be inferred from conventional nucleation theory ${ }^{24}$. When the temperature is raised with an $\mathrm{H}_{2}$ atmosphere, the reduction proceeds slowly due to a low temperature. This leads to Ostwald ripening acceleration, resulting in a particle size that is not finer, as shown in Supplementary Fig. 9. In that state, only the IrNi/C-HT sample undergoes a sufficient 

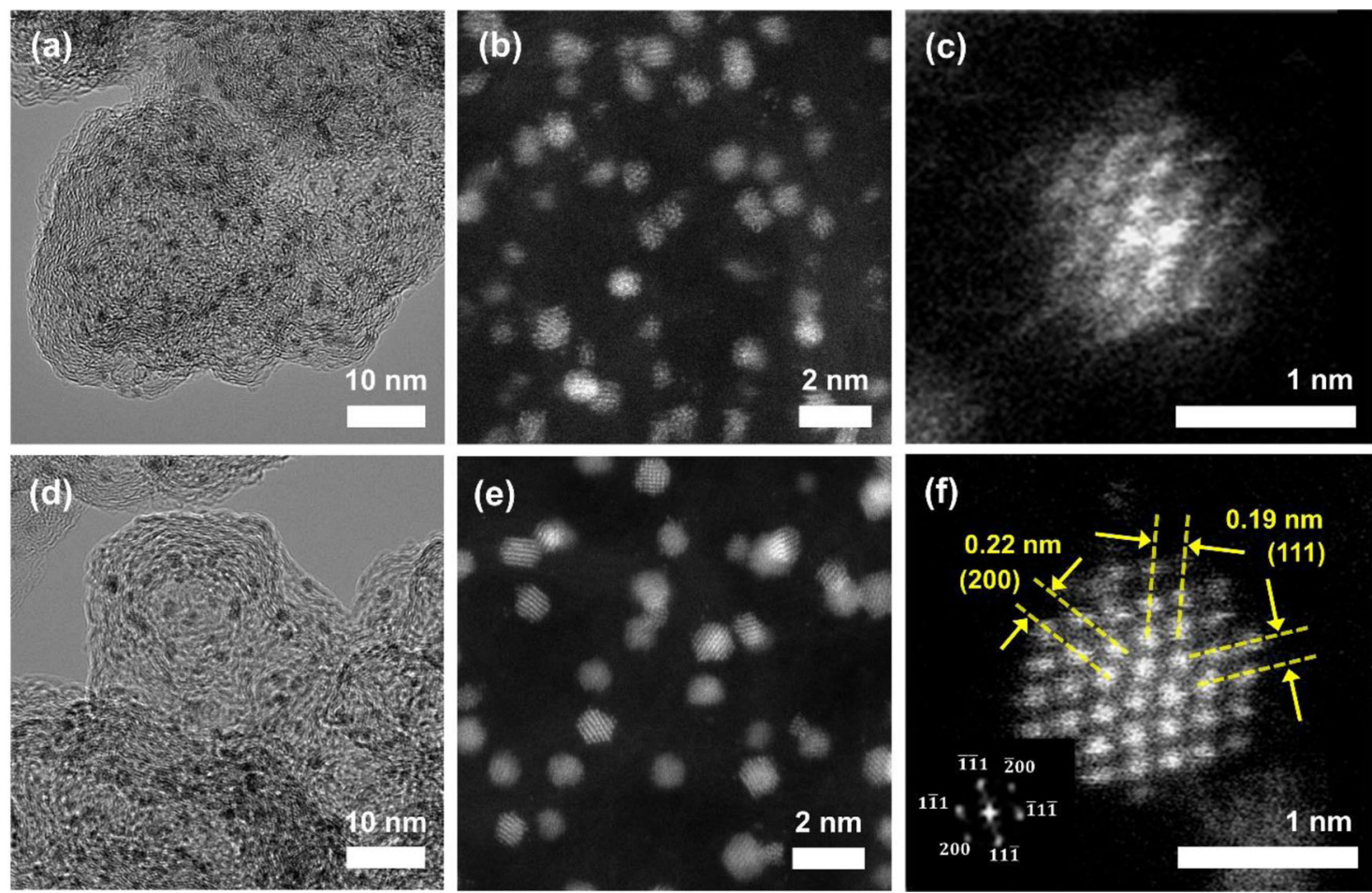

Fig. 1 Morphological and structural characteristics of the synthesized IrNi nanoparticles supported on carbon at different heat-treatment temperatures of $400{ }^{\circ} \mathbf{C}$ and $1000^{\circ} \mathbf{C}$, which are denoted as IrNi/C-LT and IrNi/C-HT, respectively. a TEM and b, c HADDF images of IrNi/C-LT. d TEM and $\mathbf{e}, \mathbf{f}$ HADDF images of IrNi/C-HT. The inserted fast Fourier transform of the IrNi/C-HT particles show the (111) and (200) planes.

crystallization step to form single-crystal nanoparticles with high crystallinity.

Electrochemical properties and catalytic activity. To investigate the effect of crystallinity on the electrochemical properties, the cyclic voltammetry $(\mathrm{CV})$ of the prepared IrNi/C-LT and IrNi/CHT was measured under changing upper potential limits (UPLs), (Fig. 2a, b and Supplementary Fig. 10). As the UPL increased during the $\mathrm{CV}$ of IrNi/C-LT, the hydrogen adsorption-desorption $\left(\mathrm{H}_{\text {upd }}\right)$ peak associated with a metallic Ir surface disappeared and two redox peaks associated with $\operatorname{Ir}(\mathrm{III}) / \operatorname{Ir}(\mathrm{IV})$ and $\operatorname{Ir}(\mathrm{IV}) / \operatorname{Ir}(>\mathrm{IV})$ emerged $^{25}$. When the UPL was decreased, the CV shape of IrNi/ C-LT was maintained. This indicated that the surface of the IrNi/ C-LT irreversibly changed from a metallic-IrNi alloy to $\mathrm{IrNiO}_{\mathrm{x}}$. In contrast, the $\mathrm{H}_{\text {upd }}$ peak area of $\mathrm{IrNi} / \mathrm{C}-\mathrm{HT}$ decreased with increasing UPL but was restored again as the UPL decreased. These findings suggested that the surface of $\mathrm{IrNi} / \mathrm{C}$-HT reversibly converted between a metallic character and an oxidic $\mathrm{IrNiO}_{\mathrm{x}}$ character. Again, a similar behavior was obvious for pure Ir/C (Supplementary Fig. 11).

Figure $2 c$ demonstrates the electrocatalytic performance of the catalysts during a set of subsequent linear voltammetric scans probing first the HER, then the OER, and then again the HER reactivity, all in $0.05 \mathrm{M} \mathrm{H}_{2} \mathrm{SO}_{4}$. Prior to the OER test, the catalysts were activated by $50 \mathrm{CV}$ cycles. During this process, an $\mathrm{IrO}_{\mathrm{x}}$ layer was generated and surface $\mathrm{Ni}$ was leached out. Compared with Ir/ $\mathrm{C}$ catalysts, IrNi/C catalysts demonstrated higher HER catalytic activity, comparable with commercial Pt/C. Ir/C-LT demonstrated a more enhanced OER performance than Ir/C-HT, due to the large amount of redox active Ir centers represented by the redox charge (Fig. 2a, b). Ir-Ni alloys generally show superior catalytic activity for the OER, regardless of their crystallinity. To evaluate metal-oxide reversibility, HER performances were remeasured after the OER test. While the IrNi/C-HT and Ir/C-HT catalysts maintained high HER reactivity, that of the $\operatorname{IrNi} / \mathrm{C}-\mathrm{LT}$ and Ir/C-LT catalysts decreased. These distinctly different levels of reversibility are reflected by the HER overpotentials (Fig. 2d) and the Tafel plots (Supplementary Fig. 11), as well. Interestingly, analogous behavioral trends were observed in the HOR/OER reversibility (Fig. 2e, f): Initial HOR performance of $\mathrm{IrNi} / \mathrm{C}$ catalysts is comparable with that of commercial $\mathrm{Pt} / \mathrm{C}$ catalyst. After $10 \mathrm{CV}$ cycles, the HOR catalytic activity of $\mathrm{IrNi} / \mathrm{C}-\mathrm{LT}$ and $\mathrm{Ir} / \mathrm{C}-\mathrm{LT}$ catalysts dropped markedly, but that of $\mathrm{IrNi} / \mathrm{C}-\mathrm{HT}$ and Ir/C-HT catalysts decreased only slightly. These results demonstrate that Ir-based nanocatalysts with high crystallinity show remarkable reversibility in their surface electrochemistry and their associated electrocatalytic reactivity for oxidation and reduction reactions, such as HER/OER and HOR/OER. To further study the catalytic reversibility of Ir-based catalysts, the HER tests were conducted for $\mathrm{Ir} / \mathrm{C}$ and $\mathrm{IrNi} / \mathrm{C}$ before and after OER by changing the heat-treatment temperature, $\mathrm{Ni}$ amount ratio, and $\mathrm{H}_{2} \mathrm{SO}_{4}$ electrolyte concentration (Supplementary Figs. 13 16). Catalytic reversibility was found both $\mathrm{Ir} / \mathrm{C}$ and IrNi/C catalysts heat-treated above $800^{\circ} \mathrm{C}$ and was not affected by alloying effect and electrolyte concentration. These results clearly reveal that reversibility is solely derived from the crystallinity of Ir not $\mathrm{Ni}$ alloy. The $\mathrm{Ni}$ element only increases the catalytic activity regardless of the crystallinity, so this reversibility study focused on the analysis of Ir materials.

Operando surface electronic structure of $\mathrm{IrNi} / \mathrm{C}$ catalysts. To explain the reversible character of the high crystallinity Ir-based catalyst, we tracked the electronic structure and oxide thickness of IrNi@IrNiO ${ }_{x}$ core-shell nanoparticles under intermittent OER and HER operating conditions using in situ/operando X-ray absorption near-edge structure (XANES) of $\mathrm{Ir}_{3}$-edge to probe electron transitions from $2 p$ to $5 d$. Since XANES is a bulk sensitivity technique, it is difficult to show the oxidation state of local structures. The white line of core-shell Ir nanoparticles represents the overall $d$-hole character, which is the redox state of both the 

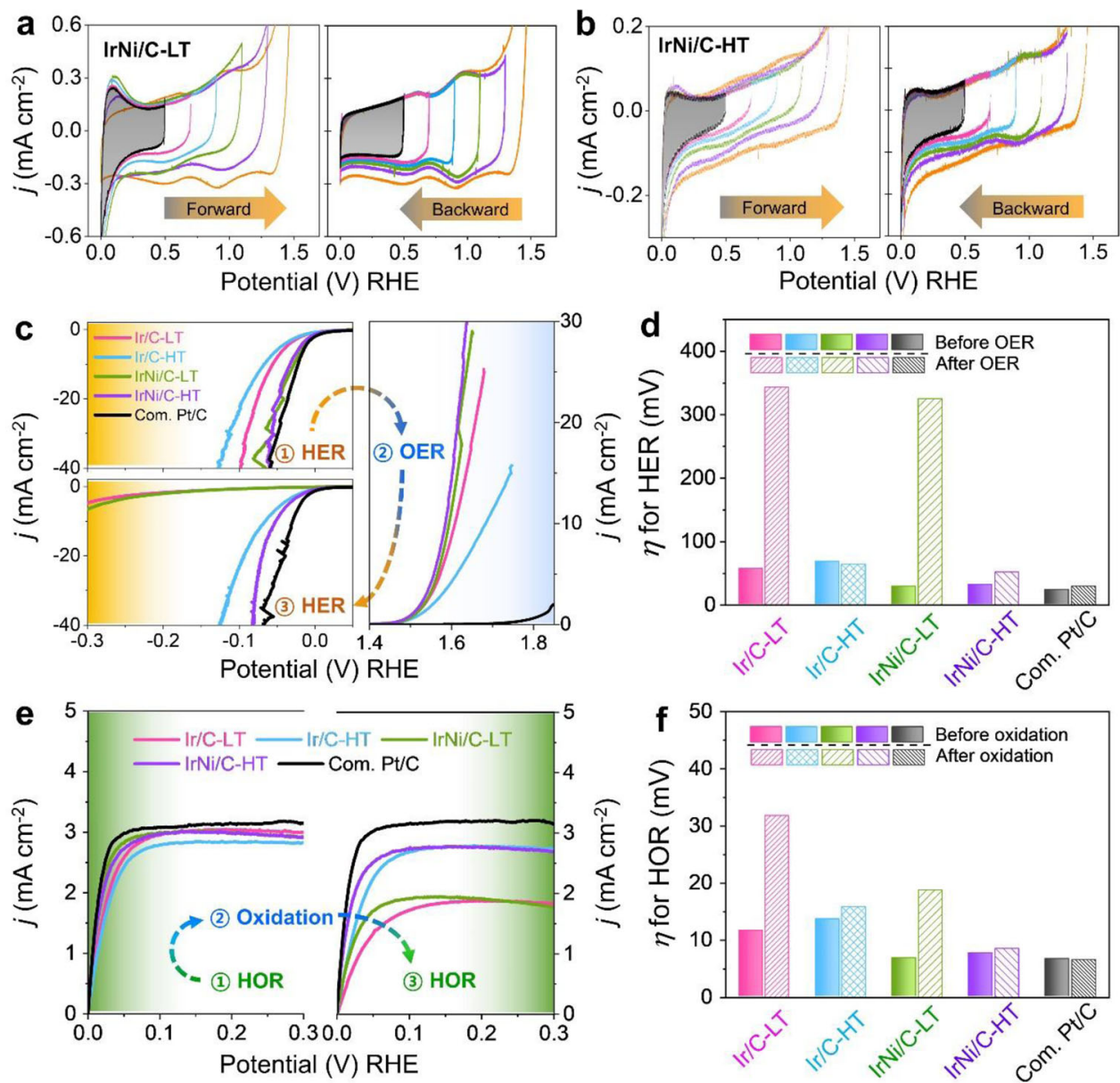

Fig. 2 Electrochemical properties and catalytic reversibility of the Ir-based electrocatalyst. Cyclic voltammetry (CV) of a IrNi/C-LT and $\mathbf{b}$ IrNi/C-HT catalyst recorded with $50 \mathrm{mV} \mathrm{s}^{-1}$ in $0.05 \mathrm{M} \mathrm{H}_{2} \mathrm{SO}_{4}$ solution. The lower potential limit (LPL) is constantly $0.05 \mathrm{~V}_{\mathrm{RHE}}$. The upper potential limit was increased from 0.5 to $1.5 \mathrm{~V}$ and decreased from 1.5 to $0.5 \mathrm{~V}$ in 200-mV steps. c iR-corrected current-potential curves for hydrogen evolution reaction (HER), oxygen evolution reaction (OER), and HER after OER. $\mathbf{d}$ Comparison between trends in activities for HER and HER after the OER test, expressed as overpotentials required for $10 \mathrm{~mA} \mathrm{~cm}^{-2}$. e iR-corrected current-potential curves for hydrogen oxidation reaction (HOR) and HOR after oxidation. Oxidation was conducted via five cycles of $\mathrm{CV}$ between 0.05 and $1.5 \mathrm{~V}$. f Comparison between trends in activities for HOR and HOR after oxidation, expressed as overpotentials required for $1 \mathrm{~mA} \mathrm{~cm}^{-2}$.

oxidized Ir in the shell and that of the metallic Ir in the core. If the core of the catalyst state is fixed to metallic-Ir, any shift of the white-line peak energy of the core-shell catalyst roughly represents a change in the $d$-band hole count of Ir in the shell (Fig. 3a) ${ }^{26}$. Moreover, if the particle size is the same, the oxide thickness of the core-shell can be roughly estimated by the whiteline area (Fig. 3b). A further detailed explanation is shown in Supplementary Note 5.

The white-line peak energy in the experimental sequence is illustrated in Fig. 3a. Under the OER condition, the white-line peak energy of both $\mathrm{IrNi} / \mathrm{C}$ catalysts is positively shifted with a $d$ band hole count of 5.4 compared with the Ir/C catalyst ( $d$-band hole count of 5.2), as shown in Fig. 3c. The $d$-band hole count was calculated by white-line peak energy and formal $d$-band hole count function (Supplementary Fig. 17). The large number of vacancies in $\mathrm{IrNiO}_{\mathrm{x}} / \mathrm{C}$ enhances the electrophilic character of oxygen, resulting in smaller kinetic barriers for OER ${ }^{26-28}$. These XANES results can explain the high activity of IrNi/C catalysts for OER. After OER and OER-HER operations, IrNi/C-LT has a higher white-line peak energy than $\mathrm{IrNi} / \mathrm{C}-\mathrm{HT}$, indicating a higher oxidation state of $\mathrm{IrNi} / \mathrm{C}-\mathrm{LT}$ after reaction. However, under HER condition, the white-line peak energy of $\mathrm{IrNi} / \mathrm{C}-\mathrm{HT}$ is higher than that of IrNi/C-LT (Fig. 3d). To explain this phenomenon, we estimated the chemical state of the catalyst under HER conditions. The HER Tafel slope of IrNi/C-HT $\left(43 \mathrm{mV} \mathrm{dec}^{-1}\right)$ indicates that the Heyrovsky step in the VolmerHeyrovsky mechanism is the rate determining step for $\mathrm{IrNi} / \mathrm{C}$ $\mathrm{HT}^{29}$. The adsorbed hydrogen $\left(\mathrm{H}_{\mathrm{ads}}\right)$ coverage is expected to be $0.25-0.50$ for the Heyrovsky step ${ }^{30}$. Based on previous research, $\mathrm{H}_{\text {ads }}$ increases the $d$-band hole count ${ }^{31,32}$. Thus, the $\mathrm{H}_{\text {ads }}$ coverage of IrNi/C-HT would slightly increase the white-line peak energy during the HER. For IrNi/C-LT, it is assumed that the $\operatorname{IrO}_{x}$ surface adsorbs protons at a cathodic potential and converts to an $\operatorname{Ir}\left(\mathrm{O}_{\mathrm{x}} \mathrm{H}_{\mathrm{y}}\right)$ species that possesses a lower $d$-band hole count than $\mathrm{IrO}_{x} 33,34$.

To observe the oxide thickness under OER/HER operating conditions, white-line areas were identified by in situ/operando XANES. Under all conditions, IrNi/C-HT catalysts showed smaller white-line areas than $\mathrm{IrNi} / \mathrm{C}$-LT catalysts, implying that $\mathrm{IrNi} / \mathrm{C}-\mathrm{HT}$ possesses a thinner $\operatorname{IrO}_{\mathrm{x}}$ layer than $\mathrm{IrNi} / \mathrm{C}$-LT during the OER and HER (Fig. 3b). In particular, the IrNi/C-HT catalyst showed a highly reduced white-line area under the HER condition (Fig. 3d), which is close to the metallic-Ir foil. Thus, IrNi/C-HT nanoparticles possess an almost metallic surface under the HER condition, leading to high HER activity. The white-line area clearly exhibits the difference between IrNi/C-HT 

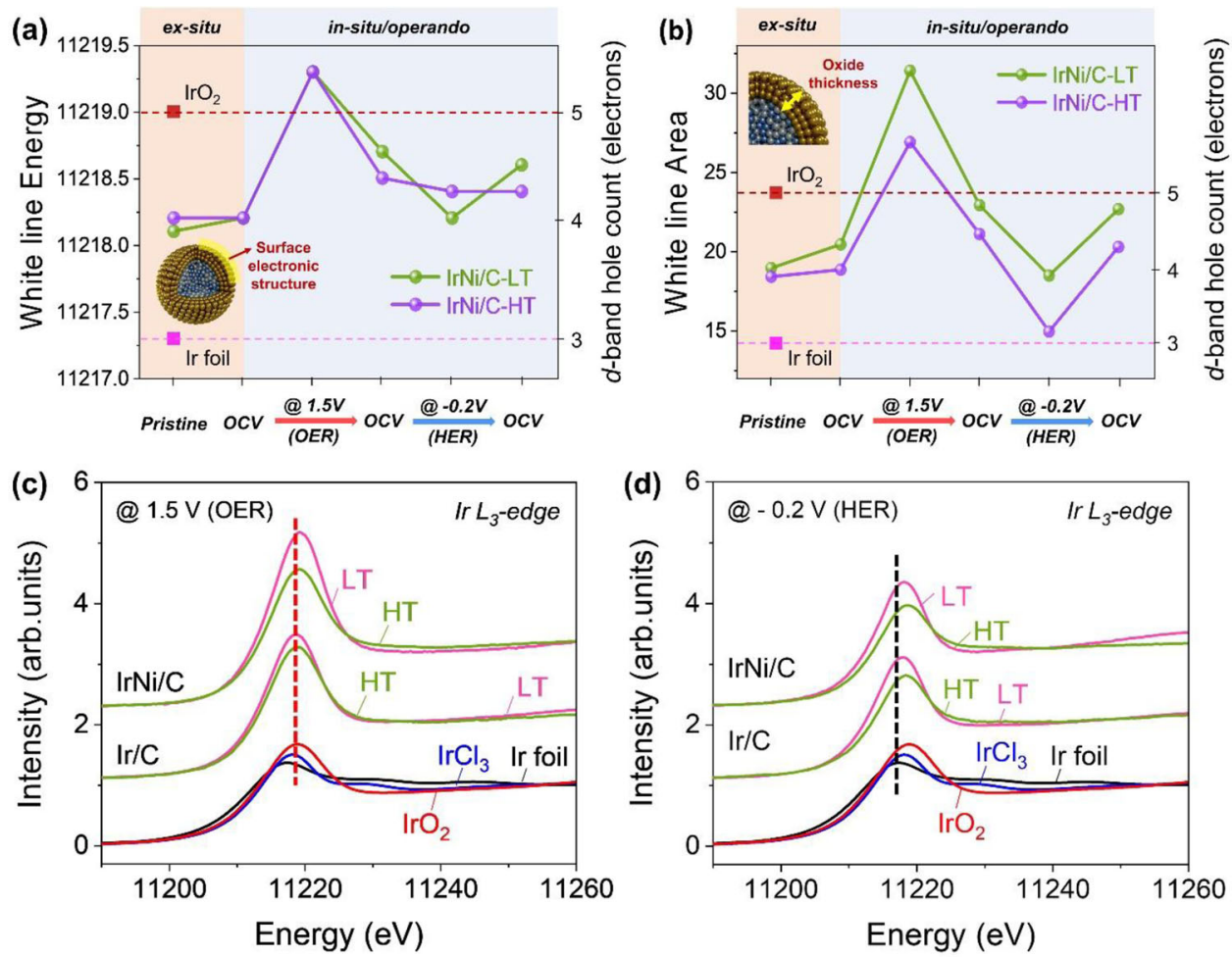

Fig. 3 In situ/operando study of Ir-based electrocatalysts for electronic structure and oxide thickness analysis. Ir L3-edge XANES of synthesized catalysts measured under the experimental sequence: (i) pristine electrocatalysts powder, (ii) spray coated on electrode in $0.05 \mathrm{M} \mathrm{H}_{2} \mathrm{SO}_{4}$ at $\mathrm{OCV}$, (iii) OER operating condition at $1.5 \mathrm{~V}_{\mathrm{RHE}}$ ( iv) OCV after OER operation, (v) HER operating condition at $-0.2 \mathrm{~V}_{\mathrm{RHE}}$ ( vi) OCV after HER operation. (a) The whiteline peak energy and (b) area of IrNi/C-LT and IrNi/C-HT are illustrated. Commercial Ir black and $\mathrm{IrO}_{2}$ were measured as references under same conditions. Ir $L_{3}$-edge XANES spectra of synthetic catalyst during (c) OER and subsequent (d) HER conditions. XANES spectra under other experimental conditions are shown in Supplementary Figs. 18 and 19.

and IrNi/C-LT under OER and HER condition. This suggests that oxide thickness is a key controlling factor of the reversibility phenomenon of IrNi@IrNiO core-shell nanoparticles with high crystallinity.

To study the effect of crystallinity on the surface electronic structure in more detail, we analyzed a depth-resolved Ir $4 f$ XPS spectra using two different levels of kinetic energy (KE). The associated inelastic mean free paths associated with KEs of $210 \mathrm{eV}$ and $550 \mathrm{eV}$ are almost 0.5 and $0.9 \mathrm{~nm}$, respectively, which represent the atomic shell layers of 2 and 3-4 Ir atoms, respectively ${ }^{35}$. The Ir $4 f$ spectrum can be deconvoluted into the three types of $\mathrm{Ir}$ species: $\mathrm{Ir}^{0}$ (metallic-Ir), $\mathrm{Ir}^{\mathrm{IV}}$ (rutile-type $\mathrm{Ir}^{\mathrm{IV}} \mathrm{O}^{\mathrm{II}}{ }_{2}$ ), and $\mathrm{Ir} \mathrm{III}^{\mathrm{III}}$ (amorphous $\left.\mathrm{Ir}^{\mathrm{III}} \mathrm{O}_{3}\right)^{19}$. The details of the deconvoluted XPS results are shown in Supplementary Table 1. The Ir depth profile of pristine $\mathrm{IrNi} / \mathrm{C}$ electrodes indicates that the majority of nanoparticles were in the metallic state with soft oxidation of the surface (Supplementary Fig. 20). After OER, the spectrum of the IrNi/C-LT catalyst at $210 \mathrm{eV} \mathrm{KE}$ is fully shifted to the position of the $100 \% \mathrm{Ir}^{\mathrm{III}}$ species (Fig. 4a). The Ir $4 \mathrm{f}$ line shape of the IrNi/C-LT catalyst at $550 \mathrm{eV} \mathrm{KE}$ is a mixture $53.2 \%$ $\mathrm{Ir}^{\mathrm{III}}$ and $46.8 \% \mathrm{Ir}^{\mathrm{IV}}$ with no metallic species, suggesting that the surface of IrNi/C-LT is completely changed to a thick amorphous $\mathrm{IrNiO}_{\mathrm{x}}$ layer. This thick amorphous $\mathrm{IrNiO}_{\mathrm{x}}$ shell of $\mathrm{IrNi} / \mathrm{C}-\mathrm{LT}$ is conserved after the HER condition, revealing an irreversible Ir oxide layer on IrNi/C-LT. Meanwhile, the composition of the $\mathrm{IrNi} / \mathrm{C}-\mathrm{HT}$ catalyst after OER is $69.6 \% \mathrm{Ir}^{\mathrm{III}}$ and $30.4 \% \mathrm{Ir}^{\mathrm{IV}}$ at 210 $\mathrm{eV} \mathrm{KE}$ and $39.4 \% \mathrm{Ir}^{\mathrm{III}}, 26.8 \% \operatorname{Ir}^{\mathrm{IV}}$, and $39.4 \% \operatorname{Ir}^{0}$ at $550 \mathrm{eV} \mathrm{KE}$ (Fig. 4b), indicating that an thin $\operatorname{IrNiO}_{\mathrm{x}}$ layer has been synthesized on the metallic subsurface. After HER, the ratio of $\mathrm{Ir}^{\mathrm{III}}$ species at $210 \mathrm{eV} \mathrm{KE}$ is significantly decreased and $38.2 \%$ metallic-Ir is observed, demonstrating that some of the thin
$\mathrm{IrNiO}_{\mathrm{x}}$ layer was turned into the metallic surface. The Ir depth profiles of $\mathrm{IrNi} / \mathrm{C}-\mathrm{LT}$ and $\mathrm{IrNi} / \mathrm{C}-\mathrm{HT}$ summarized in Fig. $4 \mathrm{c}$, clearly demonstrate that the thick $\operatorname{IrNiO}_{\mathrm{x}}$ layer of IrNi/C-LT synthesized by OER is maintained after HER and that the thin $\mathrm{IrNiO}_{\mathrm{x}}$ layer of IrNi/C-HT converts to metallic-Ir after HER.

The description of phenomena related to crystallinity and HER/HOR/OER reversibility is illustrated in Fig. 4d. IrNi/C-LT with low crystallinity exhibits an abundant grain boundary, which accelerates the penetration of ions into nanoparticles and results in the formation of a thick $\mathrm{IrNiO}_{\mathrm{x}}$ layer ${ }^{36}$. Ex-situ HAADF and EDS mapping images show that IrNi/C-LT (Supplementary Fig. 21) consists of a thick amorphous $\mathrm{IrNiO}_{\mathrm{x}}$. This thick irreversible $\mathrm{IrNiO}_{\mathrm{x}}$ demonstrates excellent performance for OER but poor performance for the HER and HOR. On the other hand, IrNi/C-HT with high crystallinity has no grain boundary defects, enabling formation of a very thin $\mathrm{IrNiO}_{\mathrm{x}}$ layer. $\mathrm{Ni}$ of $\mathrm{IrNi} / \mathrm{C}-\mathrm{HT}$ was still located with Ir, confirming the core of the metallic structure (Supplementary Fig. 22). This thin $\mathrm{IrNiO}_{\mathrm{x}}$ of IrNi/C-HT is reversibly converted to a metallic structure under HER/HOR conditions, showing high reversibility for OER/HER/HOR.

Mechanistic study of reversible catalytic activity. To further clarify the reversible reactivity character of the high crystallinity Ir-based catalyst, we correlated it to surface dissolution processes at the atomic scale and were able to uncover the underlying mechanism that leads to reversibility. To achieve this, we conducted in situ/operando ICP technique using an electrochemical flow cell ${ }^{37}$. It is well known that electrochemically prepared $\mathrm{IrO}_{\mathrm{x}}$ is irreversibly oxidized ${ }^{38-41}$. Hence, there is a need for a mechanistic study on the cause of reversible conversion of the 

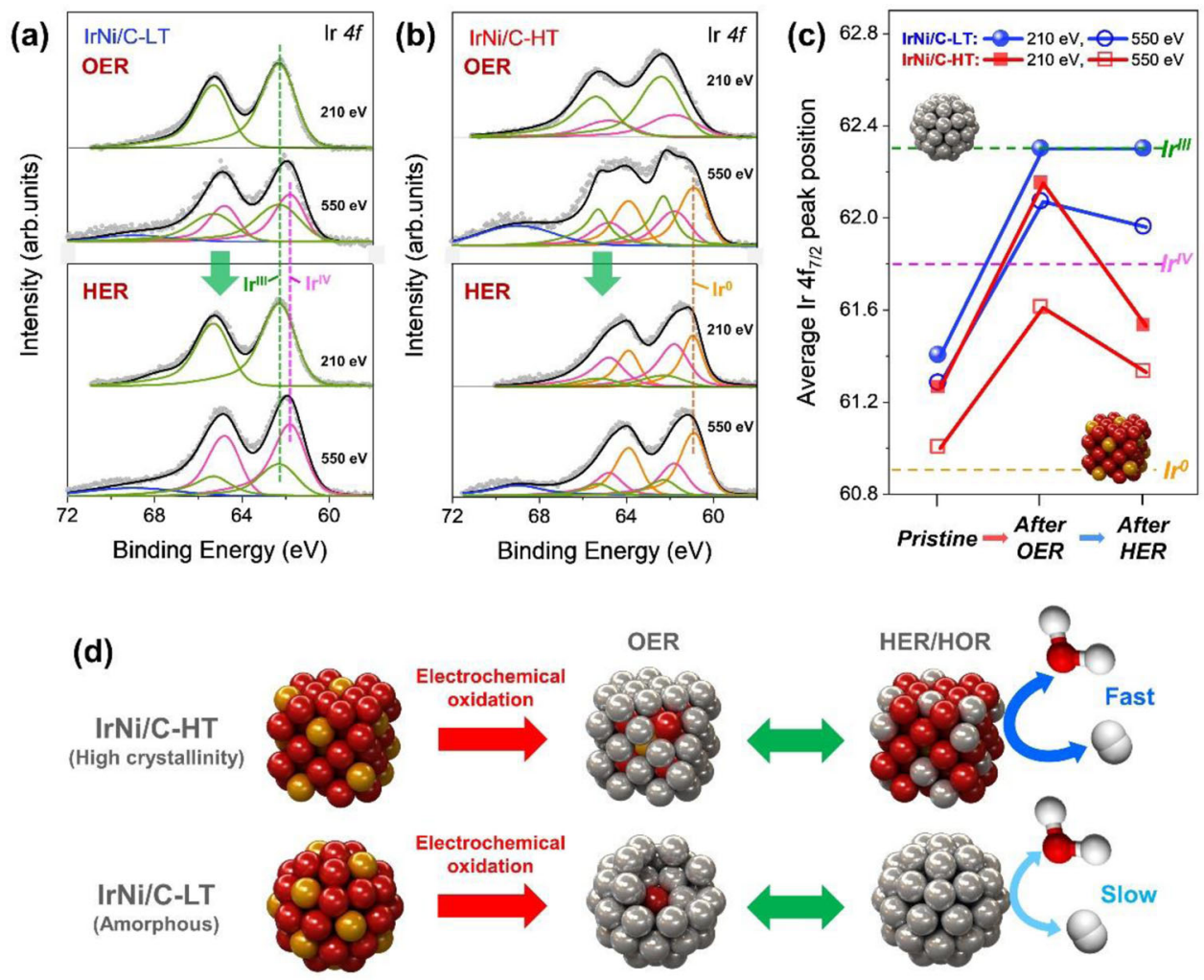

Nickel

Iridium

Oxidized Iridium

Fig. 4 Surface electronic structure of Ir-based catalysts with different crystallinities. Depth-resolved Ir $4 \mathrm{f}$ spectra of (a) IrNi/C-LT and $\mathbf{b}$ IrNi/C-HT after OER and followed by HER at photoelectron kinetic energies of 210 and $550 \mathrm{eV}$. c Average Ir $4 \mathrm{f}$ peak position of synthesized catalyst under experimental sequence with different photoelectron kinetic energies of 210 and $550 \mathrm{eV}$. d Schematic illustration of IrNi/C-LT and IrNi/C-HT under OER and HER/HOR.

$\mathrm{IrNiO}_{\mathrm{x}}$ layer on $\mathrm{IrNi} / \mathrm{C}-\mathrm{HT}$ to a metallic surface. When cycling between 0.05 and $1.5 \mathrm{~V}_{\mathrm{RHE}}$ to produce $\mathrm{IrNiO}_{\mathrm{x}}$ species on nanoparticles, IrNi/C-LT has a large peak compared to IrNi/C-HT, indicating that $\mathrm{IrNi} / \mathrm{C}-\mathrm{LT}$ possesses a large amount of amorphous $\mathrm{IrNiO}_{\mathrm{x}}$. Subsequently, three types of peaks were observed (Fig. 5a, b).

First, the peaks of OER intermediate dissolution located at the highest potential, are associated with an intermediate Ir species during the OER and lattice oxygen participation (denoted as O1 O3). For the peak area of dissolution during the OER, IrNi/C-HT is lower than that of $\mathrm{IrNi} / \mathrm{C}$-LT owing to the thin $\mathrm{IrNiO}_{\mathrm{x}}$ layer of IrNi/C-HT. To confirm stability of IrNi/C-HT during reaction, the dissolution profile under OER and HER conditions was obtained and is shown in Supplementary Fig. 23. IrNi/C-HT under OER and HER conditions showed a lower Ir dissolution than $\mathrm{IrNi} / \mathrm{C}$-LT, despite similar OER catalytic activity (Fig. 2c), demonstrating high stability of IrNi/C-HT. Second, the peaks of reversible reduction dissolution (denoted as R1 and R2) which are located close to $1.0 \mathrm{~V}_{\mathrm{RHE}}$, close to the standard potential of Ir oxidation reaction $(0.926 \mathrm{~V}+0.0591 \mathrm{pH})$, exhibited electrochemical dissolution of reversible Ir oxides. Third, the peaks of irreversible reduction dissolution (denoted as I1, I2, and I3) were located at the lowest potential, representing cathodic dissolution due to irreversible Ir oxide. Both peaks indicate the cathodic dissolution of Ir oxide. Interestingly, there is no peak of reversible reduction dissolution for IrNi/C-LT, and IrNi/C-HT after $1.3 \mathrm{~V}$. When the upper potential was increased from 1.3 to $1.5 \mathrm{~V}_{\mathrm{RHE}}$, a peak of reversible reduction dissolution was observed, indicating the production of reversible Ir oxides during the $\mathrm{OER}^{40}$. For IrNi/ $\mathrm{C}-\mathrm{HT}$, cathodic dissolution is significantly lower than that of
$\mathrm{IrNi} / \mathrm{C}$-LT, indicating that metallic surface of $\mathrm{IrNi} / \mathrm{C}-\mathrm{HT}$ is not derived by removal of $\mathrm{IrNiO}_{\mathrm{x}}$ layer through dissolution.

Mayrhofer et al. analyzed the reduction of Ir hydroxide using the in situ/operando ICP technique and suggested that cathodic dissolution can be explained by dissolution and re-deposition phenomena and/or incomplete oxide reduction ${ }^{38,39}$. Based on this hypothesis, we proposed a description of the reversible oxide film of IrNi/C-HT, as shown in Fig. 5c. The particularly small amount of cathodic dissolution of IrNi/C-HT suggests that the converted $\mathrm{IrNiO}_{\mathrm{x}}$ almost all transformed to the metallic phase, and did not dissolve into the electrolyte. IrNi/C-HT has a thin $\mathrm{IrNiO}_{\mathrm{x}}$ layer, resulting in a metallic surface after dissolution of $\mathrm{IrNiO}_{\mathrm{x}}$. The adsorbed hydrogen $\left(\mathrm{H}_{\mathrm{ads}}\right)$ on the metallic surface can serve to promote Ir reduction to metal ${ }^{42-44}$. Based on the Tafel slope, the $\mathrm{H}_{\mathrm{ads}}$ coverage expected to be $0.25 \sim 0.50$ during HER is sufficient for metal reductions. This metallic surface of IrNi/CHT served as a substrate for the deposition of dissolved Ir ions to accelerate the reduction of Ir ions to metallic-Ir, which supports the reversible property of $\operatorname{IrNi} / \mathrm{C}-\mathrm{HT}$. For IrNi/C-LT, the thick oxide layer is retained despite cathodic dissolution. The IrNi/CLT surface may have an $\operatorname{IrO}_{x} \mathrm{H}_{y}$ phase under HER conditions, leading to re-deposition of dissolved Ir ions and non-complete reduction of the oxide. Markovic et al. reported that dissolution/ re-deposition phenomena can be measured by the amount of dissolution with different sweep rates ${ }^{45}$. Fast scan rates prevent dissolved ion from diffusion layer to bulk electrolyte, leading to a lower amount of dissolved ion. Thus, a high dissolution amount ratio of slow/fast scan rate exhibits enhanced dissolution/redeposition property. The dissolution amount ratio of slow/fast scan rate of IrNi/C-HT between 0 and $1.5 \mathrm{~V}_{\mathrm{RHE}}$ is $0.310\left(\frac{0.113 \mathrm{ng}}{0.364 \mathrm{ng}}\right)$, 

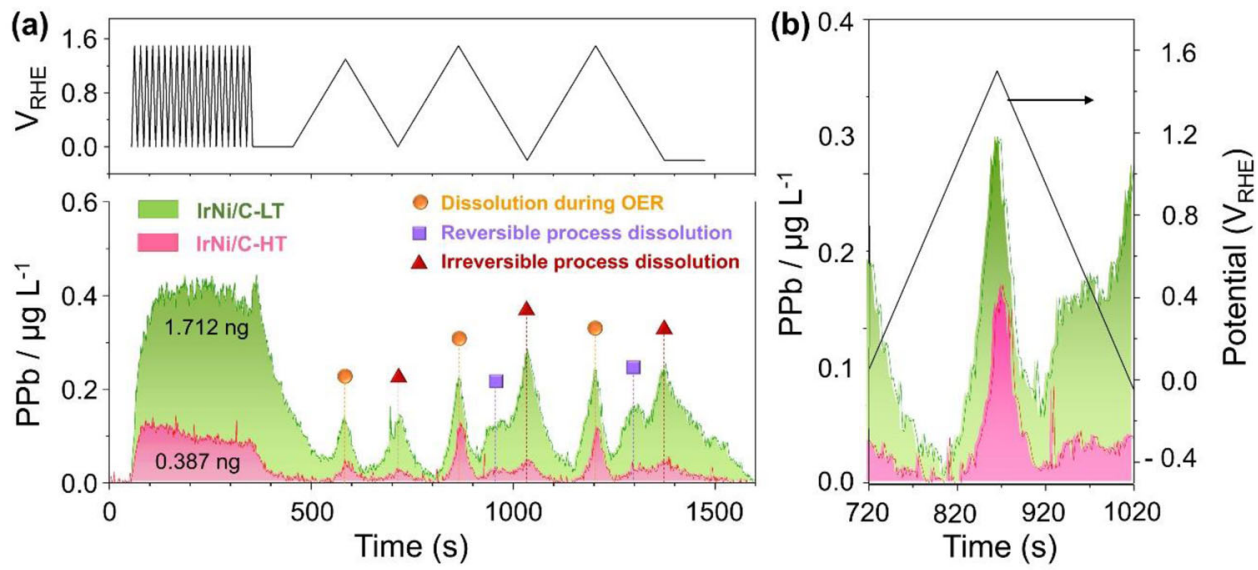

(c)
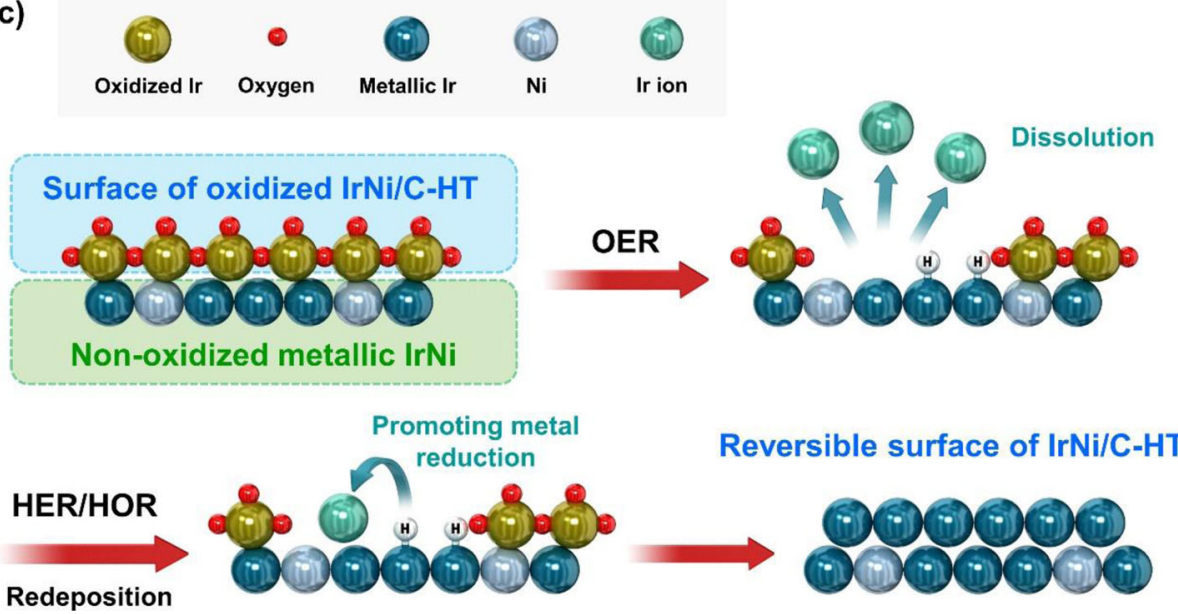

Fig. 5 Mechanistic study of the reversible catalyst surface by in situ/operando ICP of IrNi/C-LT and IrNi/C-HT. a Real-time Ir dissolution profile of IrNi/ $\mathrm{C}-\mathrm{LT}$ and IrNi/C-HT under a representative experimental sequence. $\mathbf{b}$ The Ir dissolution profile during CV in the scan range between 0 and $1.5 \mathrm{~V}_{\mathrm{RHE}}$. c Reversible surface schematic of IrNi/C-HT under OER- HER conditions.

which is higher than $0.233\left(\frac{0.381 \text { ng }}{1.634 n g}\right)$ for IrNi/C-LT (Fig. 5a, b). To further prove dissolution/re-deposition property of $\mathrm{IrNi} / \mathrm{C}-\mathrm{HT}$, $\mathrm{H}_{\text {upd }}$ peak area recovery was observed after OER and HER with different rotation rate of $\mathrm{RDE}$. As seen in the sweep rate experiment, dissolution/re-deposition phenomena were affected by dissolved ion concentration, indicating that a low rotation rate of RDE could also lead to enhanced dissolution/re-deposition properties. In Supplementary Fig. 24, the increase of $\mathrm{H}_{\text {upd }}$ peak area after HER is higher at lower rotation rate of RDE. These results indicate that the reversibility of high crystallinity catalysts was derived by a dissolution/re-deposition mechanism.

Harnessing catalytic reversibility in a large-scale single PEM fuel cell. To apply and harness the catalytic reversibility of Ir based nanoparticles with respect to the HOR and OER in a real electrochemical device, fuel starvation experiments were conducted in a single PEM fuel cell that was built using $\mathrm{IrNi} / \mathrm{C}-\mathrm{HT}$ and $\mathrm{IrNi} / \mathrm{C}-\mathrm{LT}$ as the catalytically active component in the anode catalyst layer (Fig. 6a). The initial fuel cell performance of IrNi/CLT and -HT is lower than that of the commercial Pt/C catalyst due to the lower HOR activity and metal composition (Supplementary Fig. 25). For the fuel starvation experiment, the supplied anode gas was converted from $\mathrm{H}_{2}$ to $\mathrm{Ar}$ at a current density of $100 \mathrm{~mA} \mathrm{~cm}^{-2}$. When $\mathrm{H}_{2}$ was exhausted at the anode, the anode potential of the commercial Pt/C catalyst increased to $1.8 \mathrm{~V}_{\mathrm{RHE}}$ for OER instead of HOR, leading to a reverse potential phenomenon. After $20 \mathrm{~s}$, the anode potential once more increased to $2.4 \mathrm{~V}_{\mathrm{RHE}}$ for carbon oxidation reaction (COR), as shown in Fig. 6a and Supplementary Fig. $26^{9}$. This reaction conversion was confirmed by in-situ exhaust gas analysis (Supplementary Fig. 27). In contrast, the cell voltage of both $\mathrm{IrNi} / \mathrm{C}$ cells increased and was maintained at $1.4-1.5 \mathrm{~V}$ for OER, and no $\mathrm{CO}_{2}$ gas was observed by in situ exhaust gas analysis, indicating that the high OER activity of IrNi/C catalysts prohibits corrosion of the carbon support. To observe HOR catalytic activity after fuel starvation, the fuel cell performance and impedance before and after the fuel starvation test were measured and are shown in Fig. 6b, Supplementary Figs. 25, 28, and Supplementary Table 2. The performance degradation at $0.6 \mathrm{~V}$ of commercial TKK Pt/C catalysts was $37.2 \%$ due to the carbon support corrosion. IrNi/C-LT reduced fuel cell performance by $26.9 \%$ despite no carbon corrosion, indicating low reversibility for HOR and OER. Conversely, the performance of IrNi/C-HT decreased slightly to $9.2 \%$, suggesting that the reversible catalytic activity of IrNi/C-HT works well under real fuel starvation conditions.

To confirm the reversibility of IrNi/C-LT and -HT for HER and OER under real device conditions, reverse voltage experiments were performed in a water electrolyzer, with the cell polarity changed every $20 \mathrm{~min}$ at a constant current density of $40 \mathrm{~mA} \mathrm{~cm}^{-2}$ (Fig. 6c). As shown in Fig. 6d, both catalysts were applied with the same cell voltage of $1.65 \mathrm{~V}$ to obtain $40 \mathrm{~mA} \mathrm{~cm}^{-2}$ for the first $20 \mathrm{~min}$. The cell voltage of $\mathrm{IrNi} / \mathrm{C}-\mathrm{LT}$ gradually increased whenever the polarity of the electrode was changed, but 

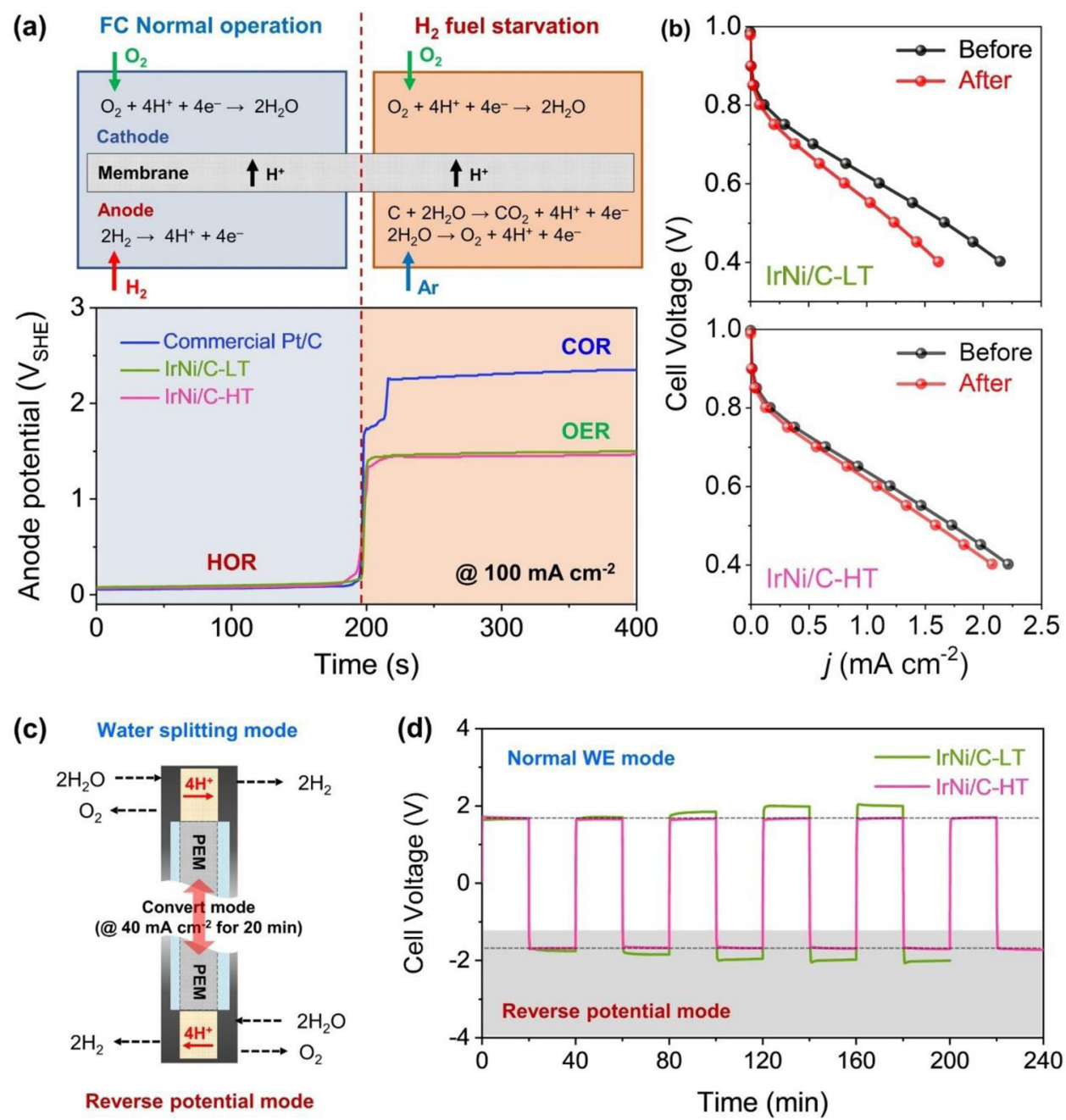

Fig. 6 Reversibility of IrNi/C-HT in water electrolysis and fuel cell systems. a Scheme of the fuel starvation experiment at fuel cell and anode potential behaviors of the commercial TKK Pt/C, IrNi/C-LT and IrNi/C-HT as the anode catalysts under the fuel starvation condition. A single fuel cell test (geometric area: $5 \mathrm{~cm}^{2}$ ) employing commercial TKK $46 \% \mathrm{Pt} / \mathrm{C}$ as the cathode. b Polarization curves of IrNi/C-HT and -LT before and after fuel starvation experiment. c Scheme of the reverse voltage experiment in water electrolyzer. d Reverse voltage experiment using IrNi/C-LT and IrNi/C-HT as anode and cathode of a single water electrolyzer (geometric area: $10 \mathrm{~cm}^{2}$ ). Galvanostatic curves obtained with current density of $40 \mathrm{~mA} \mathrm{~cm}^{-2}$.

in the case of IrNi/C-HT, the cell voltage remained stable even after 10 polarity conversions. These results demonstrate that $\mathrm{IrNi}$ / C-HT retains bifunctional catalytic activity with reversibility to HER and OER under real device conditions. Our approach promotes the reversibility of nanocatalysts that enable a variety of electrochemical reactions, which can be used as catalysts to resist the reverse voltage in fuel cells and water electrolysis systems.

\section{Discussion}

We designed a crystalline, multifunctional Ir based nano-catalyst with a remarkable reversibility in reactivity during intermittent switching between cathodic and anodic processes, such as HER/ OER/HER. We studied and clarified the underlying mechanism of the reversibility at the molecular scale using a number of different in situ/operando analysis techniques. The key to the reversibility of crystalline $\mathrm{Ir}$ alloy nanoparticles is the thin $\mathrm{IrNiO}_{\mathrm{x}}$ layers that form under OER condition. Based on the results of in situ/ operando XANES and depth-resolving XPS profiles, thin $\mathrm{IrNiO}_{\mathrm{x}}$ layers of $\mathrm{IrNi} / \mathrm{C}$-HT possess an increase in the number of $d$-band holes during OER, leading to excellent OER catalytic activity. Under HER conditions, this thin $\mathrm{IrO}_{\mathrm{x}}$ layer was reversibly converted to metallic surface, which exhibited high catalytic activity for HER. As a result, IrNi/C-HT exhibits reversible catalytic activity for OER/HER/HOR. Our in situ/operando ICP results demonstrate that the reversible $\mathrm{IrNiO}_{\mathrm{x}}$ layers emerge from a dissolution and re-deposition mechanism. The metallic IrNi alloy under the thin $\mathrm{IrO}_{\mathrm{x}}$ layer of $\mathrm{IrNi} / \mathrm{C}-\mathrm{HT}$ can be a catalytic substrate for the reduction-dissolved Ir ions under HER conditions. Based on our reverse voltage experiment in a water electrolysis cell and our fuel starvation experiment at the PEM fuel cell, the IrNi/C-HT catalyst exhibits high reversibility for HER/OER and HOR/OER under real device conditions. Our nanocatalyst design with high crystallinity can impart unique reversible properties to provide insight into various catalytic reactions and applications.

\section{Methods}

Preparation of electrocatalysts. The IrNi nanoparticles supported on carbon (denoted as IrNi/C) electrocatalysts were prepared through a modified impregnation method. Sixty milligrams of iridium nitrate (Alfa Aesar), $45 \mathrm{mg}$ of nickel acetate (Sigma Aldrich) and $260 \mathrm{mg}$ of carbon black (Ketjen Black EC-300J) were ultrasonically mixed in $20 \mathrm{~mL}$ of deionized (DI) water. The mixed solution was dried under vacuum at $80^{\circ} \mathrm{C}$. The resultant powder was subjected to heat treatment under $100 \% \mathrm{~N}_{2}(99.999 \%)$ at a flow rate of $500 \mathrm{~cm}^{3} / \mathrm{min}$ to $400{ }^{\circ} \mathrm{C}$, and then the gas was immediately changed to $10 \% \mathrm{H}_{2}(99.999 \%)$ and $90 \% \mathrm{~N}_{2}$. The temperature was maintained at $400{ }^{\circ} \mathrm{C}$ for $5 \mathrm{~min}$ under the changed gas conditions and then cooled to room temperature. The resulting powder was washed 3 times with DI water and 
then filtered and dried in a vacuum oven at $40{ }^{\circ} \mathrm{C}$ for $12 \mathrm{~h}$. The final product was denoted as IrNi/C-LT. Crystallized IrNi supported on a carbon catalyst was prepared by only varying the heat-treatment temperature to $1000^{\circ} \mathrm{C}$, and this was denoted as IrNi/C-HT. For comparison, Ir nanoparticles supported on carbon electrocatalysts synthesized at heat treatment temperatures of $400^{\circ} \mathrm{C}$ and $1000^{\circ} \mathrm{C}$ were prepared, which are denoted as Ir/C-LT and Ir/C-HT, respectively.

Materials characterization. X-ray diffraction (XRD, PANalytical, $\mathrm{Cu}$ Ka radiation) was conducted to measure the crystallinity and identify the nature of the electrocatalysts. The morphology of the synthesized catalyst was measured by highresolution transmission electron microscopy (HR-TEM) using an FEI Titan ${ }^{\text {ntw }}$ 80-300 TEM and an FEI Talos F200X. High-resolution scanning transmission electron microscopy (STEM) was performed by a Titan $80-300$, and energy dispersive X-ray spectroscopy (EDX) was conducted by a Talos F200X. The elemental composition of the catalyst was analyzed using inductively coupled plasma-optical emission spectrometry (ICP-OES, iCAP 7000, Thermo Fisher Scientific). The depth profile of the Ir nanoparticles was characterized using depth-resolved X-ray photoelectron spectroscopy (XPS) at the 4-D beamline of Pohang Accelerator Laboratory (PAL), Pohang, South Korea. For the XPS measurements, samples were prepared by spraying and drying the catalyst ink onto carbon paper (Sigracet 39 $\mathrm{BC}$ ) to prepare the electrode. After the OER, the electrodes were electrochemically treated in two steps. First, a cyclic voltammogram (CV) between 0.05 and $1.5 \mathrm{~V}_{\mathrm{RHE}}$ was performed to oxidize the electrode for 50 cycles at a scan rate of $500 \mathrm{mV} \mathrm{s}^{-1}$. Second, the OER proceeded for $10 \mathrm{~min}$ under a chronopotentiometry of $1.5 \mathrm{~V}_{\mathrm{RHE}}$. For the electrodes after HER, the previous OER-treated electrodes underwent additional chronoamperometry at $-0.2 \mathrm{~V}_{\mathrm{RHE}}$ for $10 \mathrm{~min}$.

Electrochemical analysis. Electrochemical measurements were conducted on a VSP potentiostat (Bio-Logic) in a standard three-electrode system using a rotating disk electrode (RDE, $0.196 \mathrm{~cm}^{2}$, glassy carbon, Pine Instrument) as the working electrode and a $\mathrm{Hg} / \mathrm{Hg}_{2} \mathrm{SO}_{4}$ electrode as the reference electrode. The electrochemical tests were performed in a $0.05 \mathrm{M} \mathrm{H}_{2} \mathrm{SO}_{4}$ aqueous solution. For the counter electrode, Pt wire was used for the OER and HOR, and a graphite rod was used for the HER. The measured potential was converted to a reversible hydrogen electrode (RHE) using calibration data, which were based on the CV result under $\mathrm{H}_{2}$ saturated $0.05 \mathrm{M} \mathrm{H}_{2} \mathrm{SO}_{4}$. For the RDE test, $5 \mathrm{mg}$ of catalyst was dispersed in $2.49 \mathrm{ml}$ of isopropyl alcohol (IPA), $2.49 \mathrm{ml}$ of DI water, and $0.02 \mathrm{ml}$ of $5 \mathrm{wt} \%$ Nafion ${ }^{\mathrm{TM}}$ solution (Sigma) by sonication for $20 \mathrm{~min}$. The mixed solution was loaded onto the RDE. The total Ir loading was fixed at $3 \mu \mathrm{g} \mathrm{cm}^{-2}$. Prior to the OER test, the surface of the synthesized catalyst was oxidized using cyclic voltammetry (CV) between 0.05 and $1.5 \mathrm{~V}_{\text {RHE }}$ with 50 cycles at a scan rate of $500 \mathrm{mV} \mathrm{s}^{-1}$. Ohmic resistance was measured by electrochemical impedance spectroscopy from 1000 to $0.1 \mathrm{~Hz}$ to compensate for iR loss.

Reverse voltage test in a water electrolyzer. The water electrolysis test was conducted using a $10 \mathrm{~cm}^{2}$ single-cell water electrolyzer with two symmetric electrodes as both the anode and cathode. To fabricate the electrodes, the synthesized catalyst was ultrasonically mixed with $5 \mathrm{wt} \%$ Nafion $^{\mathrm{TM}}$ ionomer in IPA for $20 \mathrm{~min}$. The prepared catalyst ink was directly sprayed onto a gold-coated Ti foam (Bekaert, 2GDL12N-50) at $90{ }^{\circ} \mathrm{C}$ using a heated vacuum table. The geometric area of the electrode was $10 \mathrm{~cm}^{2}$, and $\mathrm{Ir}$ at $0.1 \mathrm{mg} \mathrm{cm}^{-2}$ was loaded onto the electrode. The prepared electrode was used simultaneously as an anode and a cathode and was separated by a Nafion 212 membrane. The prepared membrane electrode assemblies (MEAs) were sandwiched between the current collectors and assembled in a homemade cell body. The polarization curves were measured at room temperature and atmospheric pressure. DI water was pumped to the anode and cathode sides using a peristaltic pump. For the reverse voltage experiment, $40 \mathrm{~mA}$ $\mathrm{cm}^{-2}$ was applied to the single cell, and the polarity of the electrode was reversed every $20 \mathrm{~min}$. The details of the experiment are described in Supplementary Information.

Fuel starvation test in a PEM fuel cell. The membrane electrode assemblies (MEAs) were prepared using the catalyst-coated membrane method. To fabricate the MEA, the commercial Tanaka Kikinzoku Kogyo (TKK) 46\% Pt/C catalyst was used as the cathode, and the synthesized catalysts were employed as the anode. The catalysts were ultrasonically mixed with a Nafion ${ }^{\circledR}$ solution in IPA for $20 \mathrm{~min}$ and sprayed directly onto a Nafion 212 membrane with a $5 \mathrm{~cm}^{2}$ geometric area at $90{ }^{\circ} \mathrm{C}$ using a heated vacuum table. The catalyst-coated membrane was then placed in a hot press at $140{ }^{\circ} \mathrm{C}$ for $3 \mathrm{~min}$. Pt loading at the cathode was $0.3 \mathrm{mg} \mathrm{cm}^{-2}$, and noble metal loading at the anode was $0.1 \mathrm{mg} \mathrm{cm}^{-2}$. Two Teflon gaskets were used to hold the MEA, and two gas diffusion layer (GDL) papers (Sigracet SGL 39BC) were used to diffuse the supplied gases $\left(\mathrm{O}_{2}, \mathrm{H}_{2}\right.$, and Ar). The prepared gasket, GDL and MEA were stacked and applied to a single-cell polymer electrolyte membrane fuel cell (PEMFC).

The PEM fuel cell test was conducted at $75^{\circ} \mathrm{C}$ at 1 atm with fully humidified $\mathrm{O}_{2}$ at the cathode and fully humidified $\mathrm{H}_{2}$ at the anode. The flow rate of each gas was $150 \mathrm{~cm}^{3} / \mathrm{min}$. For the fuel starvation experiment, the current density was applied at $100 \mathrm{~mA} \mathrm{~cm}^{-2}$, and the anode gas was changed from $\mathrm{H}_{2}$ to Ar to create fuel starvation conditions. The details of the experiment are described in the Supporting
Information. The polarization curve and impedance were measured before and after the fuel starvation experiment. The exhausted gas at the anode during the fuel starvation experiment was analyzed using online gas chromatography mass spectrometry (GC-MS). The potential behavior under fuel starvation conditions was measured using a hydrogen reference electrode ${ }^{9}$.

In situ/operando Ir $\mathbf{L}_{\mathbf{3}}$-edge XANES. In situ/operando XANES measurements of Ir $\mathrm{L}_{3}$-edges were performed in fluorescence mode at the $1 \mathrm{D}$ beamline of Pohang Accelerator Laboratory (PAL), Pohang, South Korea. The XANES was measured using a custom-made electrochemical flow cell ${ }^{37}$. A Pt wire and graphite rod were used as counter electrodes for the OER/HOR and HER, respectively. For the reference electrode, $\mathrm{Ag} / \mathrm{AgCl}(3 \mathrm{M} \mathrm{NaCl})$ was used. The working electrode was prepared by spraying catalyst ink, which is used for MEA, on a carbon-coated Kapton film. The XANES spectra were collected at an angle of $45^{\circ}$ with respect to the detector and beam line. The electrochemical measurements were performed in a $0.05 \mathrm{M} \mathrm{H}_{2} \mathrm{SO}_{4}$ aqueous solution. Peristaltic pumps were used to flow the electrolytes at $2 \mathrm{ml} \mathrm{min}^{-1}$. Before the measurement of in situ/operando XANES during the OER, the electrode was electrochemically oxidized by CV between 0.05 and $1.5 \mathrm{~V}_{\mathrm{RHE}}$ at a scan rate of $500 \mathrm{mV} \mathrm{s}^{-1}$ for 50 cycles. After oxidation, XAS was measured at $1.5 \mathrm{~V}_{\mathrm{RHE}}$ for in situ OER and $-0.2 \mathrm{~V}_{\mathrm{RHE}}$ for in situ HER. At each step, the catalyst was stabilized for $5 \mathrm{~min}$ before the XAS test. The acquired XANES and EXAFS data were processed using the ATHENA program. The details of the experiment are described in the Supplementary Information.

In situ/operando ICP-MS measurements. In situ/operando ICP-MS tests were conducted using a custom-made electrochemical flow cell containing a threeelectrode system ${ }^{37}$. An Ag/AgCl electrode (ALS Co., RE-3VT, $3 \mathrm{M} \mathrm{NaCl}$ ) and graphite rod were used as the reference and counter electrodes, respectively. Catalyst ink was loaded onto the glassy carbon plate as a working electrode by drop casting a total area of $0.1 \mathrm{~cm}^{2}$. During the in situ/operando ICP-MS test, $0.05 \mathrm{M}$ $\mathrm{H}_{2} \mathrm{SO}_{4}$ electrolyte was pumped at $0.8 \mathrm{ml} \mathrm{min}^{-1}$ to the flow cell, which was also connected to an inductively coupled plasma mass spectrometer (ICP-MS). Re $(1 \mathrm{ppb})$ was used as an internal standard to calibrate the Ir concentration. The details of the experiment are described in the Supplementary Information.

\section{Data availability}

The authors declare that the data supporting the findings of this study are available within the article and its Supplementary Information files. Additional data are available from the corresponding authors upon reasonable request.

Received: 2 January 2021; Accepted: 30 April 2021; Published online: 13 July 2021

\section{References}

1. Dresselhaus, M. \& Thomas, I. Alternative energy technologies. Nature 414, 332 (2001).

2. Turner, J. A. Sustainable hydrogen production. Science 305, 972-974 (2004)

3. Carmo, M., Fritz, D. L., Mergel, J. \& Stolten, D. A comprehensive review on PEM water electrolysis. Int. J. Hydrog. energy 38, 4901-4934 (2013).

4. Wang, M., Wang, Z., Gong, X. \& Guo, Z. The intensification technologies to water electrolysis for hydrogen production-a review. Renew. Sustain. Energy Rev. 29, 573-588 (2014)

5. Litster, S. \& McLean, G. PEM fuel cell electrodes. J. Power Sources 130, 61-76 (2004).

6. Brightman, E., Dodwell, J., Van Dijk, N. \& Hinds, G. In situ characterisation of PEM water electrolysers using a novel reference electrode. Electrochem. Commun. 52, 1-4 (2015).

7. Ogawa, T., Takeuchi, M. \& Kajikawa, Y. Analysis of trends and emerging technologies in water electrolysis research based on a computational method: a comparison with fuel cell research. Sustainability 10, 478 (2018).

8. Taniguchi, A., Akita, T., Yasuda, K. \& Miyazaki, Y. Analysis of electrocatalyst degradation in PEMFC caused by cell reversal during fuel starvation. J. Power Sources 130, 42-49 (2004)

9. Lim, K. H., Lee, W. H., Jeong, Y. \& Kim, H. Analysis of carbon corrosion in anode under fuel starvation using on-line mass spectrometry in polymer electrolyte membrane fuel cells. J. Electrochem. Soc. 164, F1580-F1586 (2017).

10. Jung, S.-M. et al. Selective electrocatalysis imparted by metal-insulator transition for durability enhancement of automotive fuel cells. Nat. Catal. 3 639-684 (2020).

11. Ohyama, J., Kumada, D. \& Satsuma, A. Improved hydrogen oxidation reaction under alkaline conditions by ruthenium-iridium alloyed nanoparticles. J. Mater. Chem. A 4, 15980-15985 (2016).

12. Durst, J. et al. New insights into the electrochemical hydrogen oxidation and evolution reaction mechanism. Energy Environ. Sci. 7, 2255-2260 (2014). 
13. Beni, G., Schiavone, L., Shay, J., Dautremont-Smith, W. \& Schneider, B. Electrocatalytic oxygen evolution on reactively sputtered electrochromic iridium oxide films. Nature 282, 281 (1979).

14. Reier, T., Oezaslan, M. \& Strasser, P. Electrocatalytic oxygen evolution reaction (OER) on $\mathrm{Ru}, \mathrm{Ir}$, and Pt catalysts: a comparative study of nanoparticles and bulk materials. Acs Catal. 2, 1765-1772 (2012).

15. Willinger, E., Massue, C., Schlögl, R. \& Willinger, M. G. Identifying key structural features of IrOx water splitting catalysts. J. Am. Chem. Soc. 139, 12093-12101 (2017).

16. Ooka, H. et al. Legitimate intermediates of oxygen evolution on iridium oxide revealed by in situ electrochemical evanescent wave spectroscopy. Phys. Chem. Chem. Phys. 18, 15199-15204 (2016).

17. Pfeifer, V. et al. The electronic structure of iridium oxide electrodes active in water splitting. Phys. Chem. Chem. Phys. 18, 2292-2296 (2016).

18. Massué, C. et al. Reactive electrophilic OI- species evidenced in highperformance iridium oxohydroxide water oxidation electrocatalysts. ChemSusChem 10, 4786-4798 (2017).

19. Pfeifer, V. et al. The electronic structure of iridium and its oxides. Surf. Interface Anal. 48, 261-273 (2016)

20. Strmcnik, D. et al. Improving the hydrogen oxidation reaction rate by promotion of hydroxyl adsorption. Nat. Chem. 5, 300 (2013).

21. Kuttiyiel, K. A., Sasaki, K., Chen, W.-F., Su, D. \& Adzic, R. R. Core-shell, hollow-structured iridium-nickel nitride nanoparticles for the hydrogen evolution reaction. J. Mater. Chem. A 2, 591-594 (2014).

22. Kutz, R. B. et al. Sustainion imidazolium-functionalized polymers for carbon dioxide electrolysis. Energy Technol. 5, 929-936 (2017).

23. Feng, J. et al. Iridium-based multimetallic porous hollow nanocrystals for efficient overall-water-splitting catalysis. Adv. Mater. 29, 1703798 (2017).

24. Karthika, S., Radhakrishnan, T. K. \& Kalaichelvi, P. A review of classical and nonclassical nucleation theories. Cryst. Growth Des. 16, 6663-6681 (2016).

25. Oh, H.-S., Nong, H. N., Reier, T., Gliech, M. \& Strasser, P. Oxide-supported Ir nanodendrites with high activity and durability for the oxygen evolution reaction in acid PEM water electrolyzers. Chem. Sci. 6, 3321-3328 (2015).

26. Nong, H. N. et al. A unique oxygen ligand environment facilitates water oxidation in hole-doped IrNiO x core-shell electrocatalysts. Nat. Catal. 1, 841 (2018).

27. Nong, H. N., Gan, L., Willinger, E., Teschner, D. \& Strasser, P. IrOx core-shell nanocatalysts for cost-and energy-efficient electrochemical water splitting. Chem. Sci. 5, 2955-2963 (2014).

28. Reier, T. et al. Molecular insight in structure and activity of highly efficient, low-Ir Ir-Ni oxide catalysts for electrochemical water splitting (OER). J. Am. Chem. Soc. 137, 13031-13040 (2015).

29. Shi, Y. \& Zhang, B. Recent advances in transition metal phosphide nanomaterials: synthesis and applications in hydrogen evolution reaction. Chem. Soc. Rev. 45, 1529-1541 (2016).

30. Li, Y. et al. MoS2 nanoparticles grown on graphene: an advanced catalyst for the hydrogen evolution reaction. J. Am. Chem. Soc. 133, 7296-7299 (2011).

31. Gorczyca, A. et al. Monitoring morphology and hydrogen coverage of nanometric $\mathrm{Pt} / \gamma-\mathrm{Al}_{2} \mathrm{O}_{3}$ particles by in situ HERFD-XANES and quantum simulations. Angew. Chem. 126, 12634-12637 (2014).

32. Singh, J., Nelson, R. C., Vicente, B. C., Scott, S. L. \& van Bokhoven, J. A. Electronic structure of alumina-supported monometallic Pt and bimetallic PtSn catalysts under hydrogen and carbon monoxide environment. Phys. Chem. Chem. Phys. 12, 5668-5677 (2010).

33. Pedersen, A. F. et al. Operando XAS study of the surface oxidation state on a monolayer IrO $\mathrm{x}$ on $\mathrm{RuO} \mathrm{x}$ and $\mathrm{Ru}$ oxide based nanoparticles for oxygen evolution in acidic media. J. Phys. Chem. B 122, 878-887 (2018).

34. Hillman, A. R., Skopek, M. A. \& Gurman, S. J. X-Ray spectroscopy of electrochemically deposited iridium oxide films: detection of multiple sites through structural disorder. Phys. Chem. Chem. Phys. 13, 5252-5263 (2011).

35. Tanuma, S., Powell, C. J. \& Penn, D. R. Calculations of electorn inelastic mean free paths. II. Data for 27 elements over the 50-2000 eV range. Surf. Interface Anal. 17, 911-926 (1991).

36. Li, T. et al. Atomic-scale insights into surface species of electrocatalysts in three dimensions. Nat. Catal. 1, 300 (2018).

37. Lee, W. H. et al. Carbon-Supported IrCoOx nanoparticles as an efficient and stable OER electrocatalyst for practicable CO2 electrolysis. Applied Catalysis B: Environmental, 118820 (2020)

38. Cherevko, S., Geiger, S., Kasian, O., Mingers, A. \& Mayrhofer, K. J. Oxygen evolution activity and stability of iridium in acidic media. Part 1.-Metallic iridium. J. Electroanalytical Chem. 773, 69-78 (2016).

39. Cherevko, S., Geiger, S., Kasian, O., Mingers, A. \& Mayrhofer, K. J. Oxygen evolution activity and stability of iridium in acidic media. Part 2.-Electrochemically grown hydrous iridium oxide. J. Electroanal. Chem. 774, 102-110 (2016).
40. Jovanovič, P. et al. Electrochemical dissolution of iridium and iridium oxide particles in acidic media: transmission electron microscopy, electrochemical flow cell coupled to inductively coupled plasma mass spectrometry, and X-ray absorption spectroscopy study. J. Am. Chem. Soc. 139, 12837-12846 (2017).

41. Geiger, S. et al. The stability number as a metric for electrocatalyst stability benchmarking. Nat. Catal. 1, 508 (2018).

42. El Sawy, E. N. \& Birss, V. I. Nano-porous iridium and iridium oxide thin films formed by high efficiency electrodeposition. J. Mater. Chem. 19, 8244-8252 (2009).

43. El Sawy, E. N. \& Birss, V. I. A comparative study of the electrodeposition of nanoporous Ir and Pt thin films. J. Electrochem. Soc. 160, D386-D393 (2013).

44. Le Vot, S., Roué, L. \& Bélanger, D. Electrodeposition of iridium onto glassy carbon and platinum electrodes. Electrochim. Acta 59, 49-56 (2012).

45. Lopes, P. P. et al. Dynamics of electrochemical Pt dissolution at atomic and molecular levels. J. Electroanal. Chem. 819, 123-129 (2018).

\section{Acknowledgements}

This work was supported by the Korea Institute of Science and Technology (KIST) institutional program, "Next Generation Carbon Upcycling Project" (Project No. 2020M1A2A6079141) and "Carbon to X Project" (Project No. 2020M3H7A1098229) through the National Research Foundation (NRF) funded by the Ministry of Science and ICT, Republic of Korea. P. S. acknowledges funding by the German Research Foundation (DFG) under Grant STR 596/11-1 and the German Federal Ministry of Education and Research (BMBF) through the project HyThroughGen within the technology platform $\mathrm{H}_{2}$ Giga (grant 03HY108D). We also acknowledge the Operando Laboratory at KIST for in situ/operando ICP-MS and Advanced Analysis Center at KIST for the TEM and XPS measurements. We wish to thank 1D XRS KIST-PAL beamline and 4D beamline for measuring the XAS and depth-resolved XPS, respectively.

\section{Author contributions}

W.H.L. designed/conducted the experiments, analyzed the data, and wrote the manuscript. Y.J.K.contributed to the HR-TEM analysis. J.H. and H.K. contributed to the fuel cell tests. K.H.C. contributed to the XANES/EXAFS analysis. Y.J.H., C.H.C. and B.K.M. provided an idea for the electrochemical analysis. P.S. and H.O. supervised the research and wrote the manuscript. All authors reviewed the manuscript.

\section{Competing interests}

The authors declare that they have no competing interests.

\section{Additional information}

Supplementary information The online version contains supplementary material available at https://doi.org/10.1038/s41467-021-24578-8.

Correspondence and requests for materials should be addressed to P.S. or H.-S.O.

Peer review information Nature Communications thanks the anonymous reviewers for their contributions to the peer review of this work. Peer review reports are available

Reprints and permission information is available at http://www.nature.com/reprints

Publisher's note Springer Nature remains neutral with regard to jurisdictional claims in published maps and institutional affiliations.

Open Access This article is licensed under a Creative Commons Attribution 4.0 International License, which permits use, sharing, adaptation, distribution and reproduction in any medium or format, as long as you give appropriate credit to the original author(s) and the source, provide a link to the Creative Commons license, and indicate if changes were made. The images or other third party material in this article are included in the article's Creative Commons license, unless indicated otherwise in a credit line to the material. If material is not included in the article's Creative Commons license and your intended use is not permitted by statutory regulation or exceeds the permitted use, you will need to obtain permission directly from the copyright holder. To view a copy of this license, visit http://creativecommons.org/ licenses/by/4.0/

(C) The Author(s) 2021 